\title{
UNDERSTANDING THE EFFECTS OF LARGE STORMS ON DOMINICA: AN ANALYSIS USING GIS AND REPEAT PHOTOGRAPHY
}

MARCUS HILL, Oberlin College

Research Advisor: Amanda Schmidt

\section{INTRODUCTION}

Understanding the full extent to which landscapes change over extended periods of time due to natural and anthropogenic causes is a challenging task. An image can start to come together using existing data, but it is difficult to contextualize an environment from numeric values alone. Keeping track of the progression of a site over time is important and provides potential information for the future. One methodology employed in the past which produces measurable and meaningful results is the use of repeat photography (Bierman, 2007; Frankl et al., 2011; Hoffman, 2010; Khan et al., 2013; Webb et al., 2010). Depending on how the method is implemented, both temporal and spatial data can be obtained from a series of photographs. To see the best results over a specific area, the location and time interval between photos have to robust and considerate of the features encompassed (Grove et al., 2013). For this study we documented the changes experienced across Dominica before and after Hurricane Maria in 2018 and Tropical Storm Erika in 2015.

The geomorphic history — and current status - of Dominica is absent from most published research ( $\mathrm{Rad}$ et al., 2006). The small $\left(750 \mathrm{~km}^{2}\right)$ island is located in the Lesser Antilles, in the southern Caribbean. It is situated on the convergent plate boundary between the subducting North American Plate and the overriding Caribbean plate, with nine potentially active volcanic sites (Long, 2017). Government provided data indicates an average annual rainfall ranging from $1,700-2,650 \mathrm{~mm}$ across the island. Located in a tropic climate, Dominica experiences a wet season ranging from mid-June to mid-November, and dry season beginning in late January to the middle of April, although it rains regularly year around (Dominica Meteorological Service, 2018). The island is over $85 \%$ vegetated and has an average slope of 19 degrees (Jimerson, this volume).

There have been 14 hurricanes which have crossed the island from 1880 - 2000 according to NOAA records (2017). In the recent past there have been two large events, Tropical Storm Erika in 2015 and Hurricane Maria in 2017. These events caused wide-spread changes to the island including inducing landslides, felling trees, and likely impacting all of the water systems on Dominica. These changes can be most evidently seen within the rivers and channels across the island over time. Using images taken over several years, both temporal and spatial comparisons were made. Conditions like average grain size, channel width, and vegetation density are compared within each channel individually over each field season. This specificity allows for broader, channel to channel comparisons to be made. To compliment the islandwide approach of understanding the effects these storm systems had on Dominica, a GIS analysis of the landslides visible from satellite imagery was also conducted.

\section{METHOD}

Google Earth Pro was used to identify the presence and relative magnitudes of landslides on the island prior to Hurricane Maria; any disturbance in vegetated features that did not appear to be anthropogenic in origin was noted. The imagery provided by Google 
Earth Pro ranges in age from 2015-2017, within this paper I refer to it all as Summer 2017 data. A qualitative assessment of age of these features was recorded to attempt to discern more recent features from older events which still visually affected the landscape. This same process was repeated using satellite imagery provided after both Tropical Storm Erika and Hurricane Maria had passed over the island. We then transferred these points into ArcGIS to begin qualitatively assessing the affect these events had on the landscape.

We identified the 20 largest watersheds on Dominica prior to arrival to obtain representative information from the entire island. At each location we photographed distinguishing and characteristic features, such as: channel width, sediment size, human activity/construction, water clarity, etc. Every location within these previously identified 20 watersheds was sampled both during June 2017 and January 2018. Samples and pictures taken during the summer field season begin with DM-0XX while the winter seasons samples begin with DM-1XX. We also conducted an in-depth analysis of the Roseau watershed, DMX20, with eleven more samples collected along the mainstem and tributaries of the Roseau river. Within this analysis, thirteen locations were sampled during earlier field expeditions in either 2014 or 2015. These photosets are particularly useful as they capture both before and after Tropical Storm Erika and Hurricane Maria.

While searching for evidence of landslides, there were noticeable patches across the island with missing foliage and uprooted or bare trees visible from satellite. These instances were noted alongside the post Maria landslides, although no such indication was visible for the analysis conducted over the summer. Post Maria satellite imagery for the island was also blocked by clouds in certain regions. This prevented fully accurate datasets from being created and can be seen sparse coverage for much of DM-X09, DMX015, DM-X016, DM-X018 (Fig. 1). This makes it difficult to accurately determine if there is actually a preference for debris flows on the western coast.

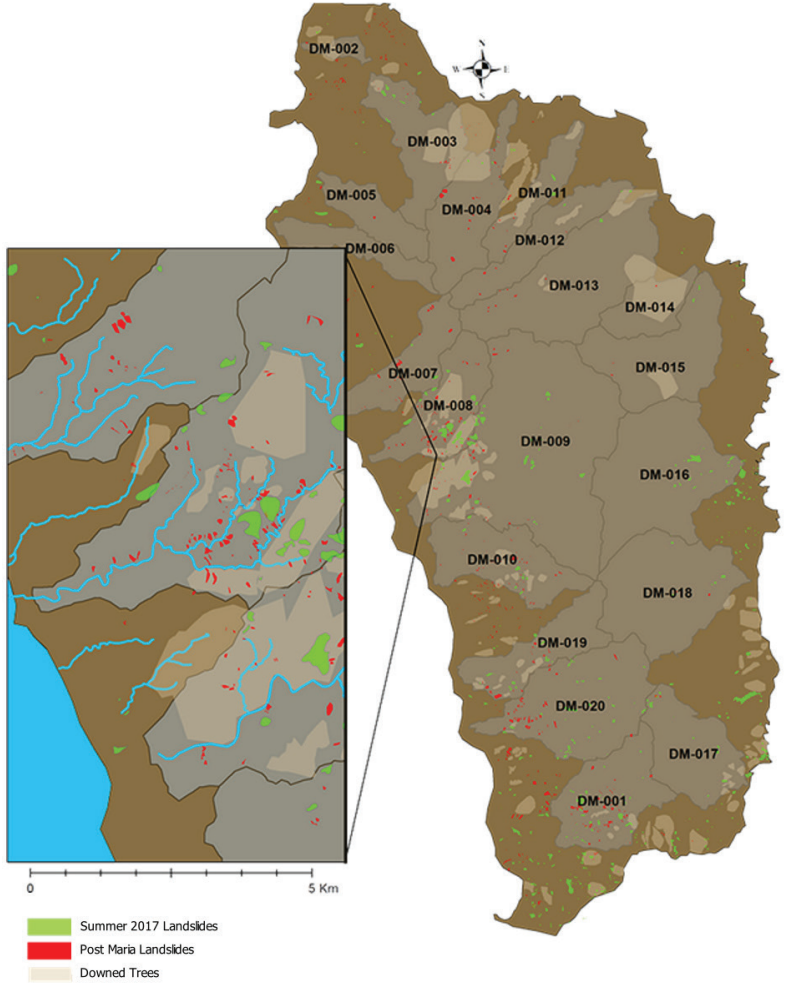

Figure 1. Map view of Dominica indicating regions of visible earth present from satellite imagery from each field season, shown in red and green. Brown regions indicate felled or barren trees.

\section{GIS RESULTS}

The landslide analysis results indicate a strong westward trend for the development of landslides on the island (Fig. 1). Within both image sets that were analyzed, more than half of the mass wasting events occurring on the island took place on the western coast, accounting for $58 \%$ of the summer 2017 events and $77 \%$ after Maria. Figure 1 also shows that 672 landslides occurred after Hurricane Maria compared to the 486 seen in the summer of 2017. The trends for each set of events noticeably differed when looking at average size and elevation. While there were more landslide events after the hurricane, they tended to be smaller in comparison to what was seen in the summer. The number of events resulting from the hurricane increased with elevation until reaching its peak at $300-400 \mathrm{~m}$, whereas the peak for the earlier landslides was at 100-200 m. (Fig. 2). 


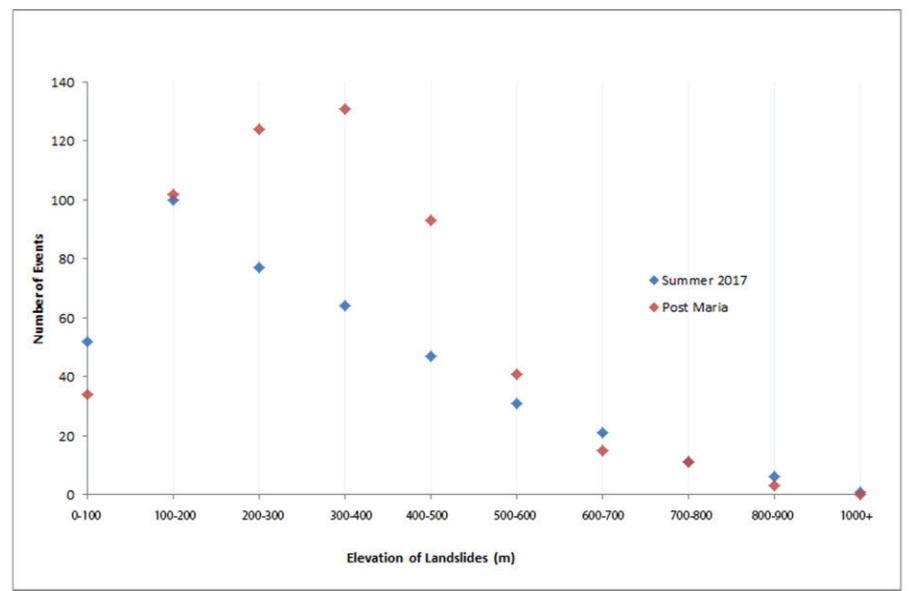

Figure 2. Frequency of events against the average elevation of landslides. Google Earth satellite imagery (Summer 2017) and satellite images available following Hurricane Maria (Post Maria)

\section{PHOTOGRAPHY RESULTS}

As the majority of the images were taken at the same location during the trip in January as the ones taken in June, many environmental conditions can be seen changing across the island. Within the 20 watersheds, 16 of them displayed a significant increase in the presence of gravel to cobble sized material, while three-DM-X07, DM-X09, and DM-X13 - showed little to no variation, and one, DM-X12, showed reduced presence of cobbles (Fig. 3). There was a significant increase in the presence of boulder-size rocks compared to what was seen over the summer within DM-X01, DM-X05, DM-X06, DM-X10, and $\mathrm{DM}-\mathrm{X} 12$. Aside from DM-X12, these previously mentioned sites are all on the west coast of Dominica. DM-X17 was the only site to have fewer boulders in or near the channel during the post-Maria visit than it had during the summer (Fig. 4).

There was widespread loss of vegetation due to Hurricane Maria. DM-X01, DM-X06, DM-X10, DM-X12, DM-X15, DM-X16, DM-X18 and DM$\mathrm{X} 09$ all experienced severe vegetative loss, with very apparent changes to bank structure, size and location (Fig. 3, Fig 4). Of these eight locations, four were on each coast of Dominica. Most of these sites converted previously dirt banks into elongated cobble bars or flood plain structures. Seven of the remaining twelve locations appeared to be mostly the same in both seasons, and the last five sites show mild-to-moderate loss of plant material.

Channel size varied noticeably across the field seasons for twelve sites as well (Fig. 3). Eight of these twelve sites became much wider while four became narrower. DM-X07 was unique in that it changed channels, reoccupying a previously deserted one. Five of the seven streams that became wider were found

\begin{tabular}{|c|c|c|c|c|c|c|}
\hline Sample & Cobbles Present & Boulders Present & Vegetation & Channel size & Channel path & Coast \\
\hline DM-X01 & yes, more & yes & severe loss & much wider & curved & West \\
\hline $\mathrm{DM}-\mathrm{X02}$ & yes, more & fewer than before & moderate loss & Slightly wider to no change & straight/step pool & West \\
\hline DM-X03 & yes, more & no & Minor to no loss & Slightly wider to no change & straight/step pool & East \\
\hline DM-X04 & yes, more & no & moderate loss & much wider & curved & East \\
\hline DM-X05 & yes, more & yes & moderate loss & Slightly wider to no change & slightly curved & West \\
\hline DM-X06 & yes, more & yes & severe loss & much wider, deeper & curved & West \\
\hline $\mathrm{DM}-\mathrm{X07}$ & Little to no change & no & Minor to no loss & wider, jumped & straight & West \\
\hline DM-X08 & yes, more & no & Minor to no loss & much wider, deeper & curved & West \\
\hline DM-X09 & Little to no change & no & Minor to no loss & Slightly wider to no change & curved & West \\
\hline DM-X10 & yes, more & yes & severe loss & much wider & straight/steps & West \\
\hline DM-X11 & yes, more & no & moderate loss & narrower & curved & East \\
\hline $\mathrm{DM}-\mathrm{X12}$ & fewer, but larger & yes & severe loss & much wider & curved & East \\
\hline DM-X13 & Little to no change & no & Minor to no loss & Slightly wider to no change & curved & East \\
\hline $\mathrm{DM}-\mathrm{X} 14$ & yes, more & no & moderate loss & Slightly wider to no change & curved & East \\
\hline $\mathrm{DM}-\mathrm{X} 15$ & yes, more & no & severe loss & narrower & curved & East \\
\hline DM-X16 & yes, more & no & severe loss & narrower & straight & East \\
\hline DM-X17 & yes, more & fewer than before & Minor to no loss & much wider & straight & East \\
\hline DM-X18 & yes, more & no & severe loss & Slightly wider to no change & straight & East \\
\hline DM-X19 & yes, more & no & severe loss & narrower & curved & West \\
\hline DM-X20 & yes, more & no & Minor to no loss & Slightly wider to no change & curved & West \\
\hline $\mathrm{DM}-\mathrm{X} 21$ & Little to no change & yes & severe loss & Slightly wider to no change & straight & West \\
\hline DM-X22 & yes, more & fewer than before & moderate loss & much wider & straight & West \\
\hline DM-X23 & fewer, but larger & yes & moderate loss & narrower & slightly curved & West \\
\hline DM-X24L & yes, more & yes & severe loss & narrower & slightly curved & West \\
\hline DM-X25R & yes, more & yes & severe loss & wider & slightly curved & west \\
\hline DM-X26 & yes, more & no & moderate loss & wider & curved & west \\
\hline $\mathrm{DM}-\mathrm{X27}$ & Little to no change & no & severe loss & Slightly wider to no change & curved & west \\
\hline DM-X28 & Little to no change & no & Minor to no loss & Slightly wider to no change & straight/step pool & west \\
\hline
\end{tabular}

Figure 3. Comparisons of the features seen in the repeat photography between 2017 and 2018. 


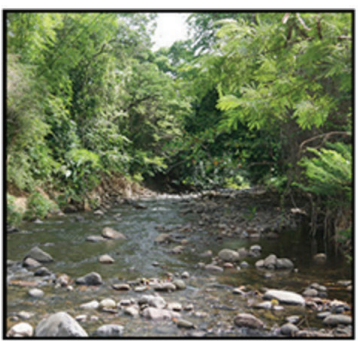

2014

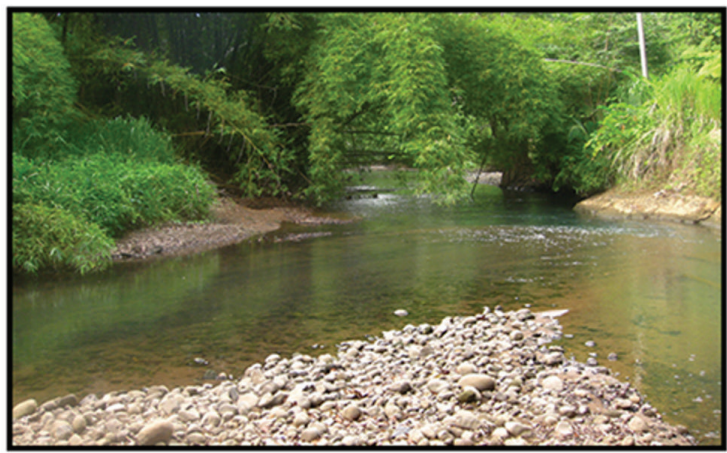

2017

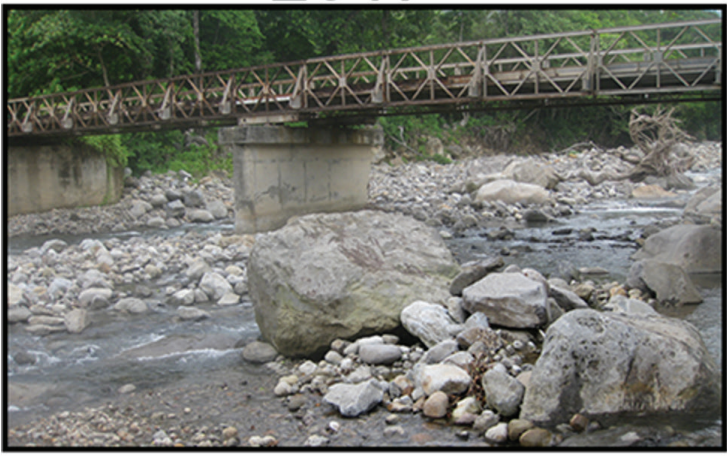

2017

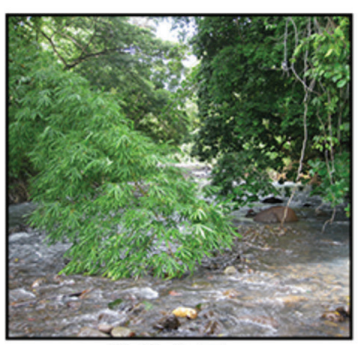

2017

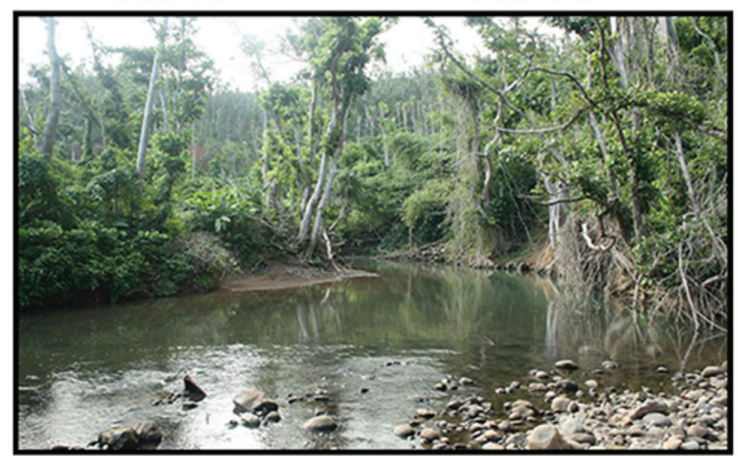

2018

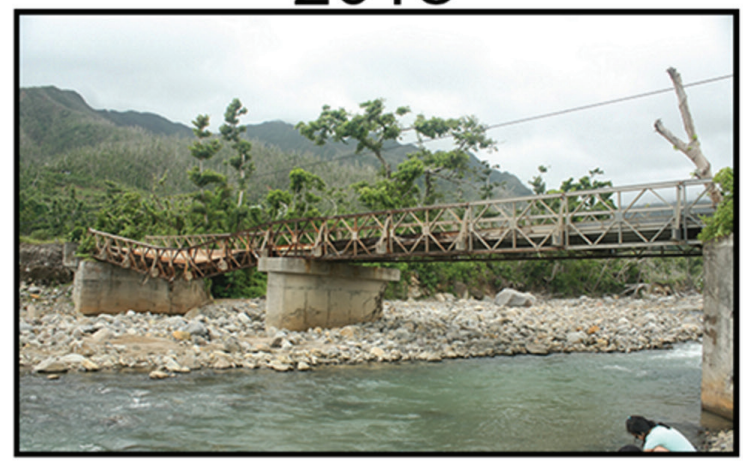

2018

Figure 4. Images in order from top to bottom: DM-X10, DM-X03, DM-X17. DM-X10 showcases the development of cobble banks, DM-X03 is relatively unchanged environment and DM-X17 shows the expulsion of boulders from the channel.

in watersheds on the west coast of the island. Three of the four streams which became narrower were on the east coast. While resampling, it was noted that many of the channels became much more sinuous than what was seen over the summer. Thirteen of the twenty channels have noticeably changed shape or direction. Of the seven that remained straight, three began developing a step-pool structure. There was no noticeable trend to determine on which side of the island these transformations took place.

As the first set of information was gathered during the wet season and the second set was during the dry, accurate comparisons and assessments of water depth and speed cannot be made. I will note, however, that generally the rivers were all deeper despite it being the dry season. Specifically, at the four locations where the channels became narrower the stream was much more deeply incised.

The trends within the Roseau watershed mirrored the patterns exhibited across the rest of the island. Significant vegetation loss, widening of the channels, evidence of larger sediment in the channel ranging from cobbles to boulders and creation of cobble banks. There was also a fairly large gradient in the amount of variability experienced across the sites; DM-X24L was unrecognizable between the two seasons while DM-X20 was extremely similar to the conditions over the summer. 


\section{DISCUSSION}

The satellite imagery analysis demonstrates frequent, small to medium scale alterations to the surface of island resulting from the storm. The frequent and shallow nature of the landslides depicted in Figure 1 agrees with the findings of Bucknam et al. and their case study of the landslides produced on Guatemala as a result of Hurricane Mitch (2001). Shallow debris flows were the most common resulting feature from the storm, present in large quantities across the environment. The magnitude and longevity of the storm seem to play important roles in understanding the types of mass-wasting events that will occur. Just as Hurricane Mitch did with Guatemala, Tropical Storm Erika lingered over Dominica for a prolonged period of time, compared to the faster nature of Hurricane Maria. Although Hurricane Maria was more powerful, because the rainfall was not as sustained as what was experienced with Erika, fewer large masswasting events could happen.

There was significant channel change across the island. DM-X07 was one of the most interesting locations to resample as it was the only place which completely changed original channels. Figure 5 describes the channel as seen in the summer with the darker blue line and what was seen in January with the lighter blue line. There is evidence that extreme flooding conditions which also induce landslides can reroute waterflow into previously abandoned channels (Wang et al., 2015; Tiron et al., 2009). This may likely be the case of a cut-off resulting from a debris-flow, as Figure 1 shows there are a number of landslides within this particular watershed.

The GIS findings indicate that the geomorphic processes on the island respond differently depending on the severity of the storms. Figures 1 and 2 highlight the variation in landslide frequency, presence and elevation between each field season. Hurricane Maria induced a greater number of landslides at a much higher average elevation than what was seen with the summer landslide data. Despite these differences, both Figure 1 and 3 generally report a westerly storm preference across the island, although these data are disputed by local accounts from islanders. Several anecdotal accounts argue that the eastern portion of Dominica experienced Hurricane Maria more

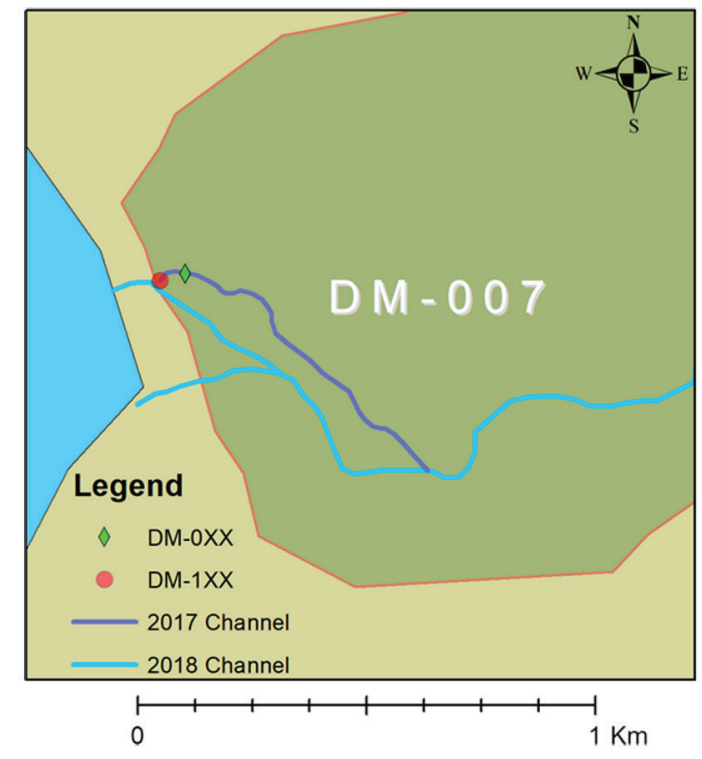

Figure 5. The only location among our sample sites to have completely changed original channels between field seasons.

dramatically, which could be supported with some of the changes seen in Figure 3.

It is difficult to determine if one side of Dominica was more greatly affected than the other. The presence of large $(1 \mathrm{~m}+$ sized) boulders in river channels was primarily restricted to the islands western streams. Only two of the seven instances where channel development indicated the movement of these materials occurred on the east coast. One of the two instances on the east coast was the removal of these boulders from the channel (Fig. 3). While the water did not appear to be able to move such massive rocks at the time of sampling, they were able to at some point during the storm. This would allow for the assumption of other water channels based along the east coast to move similar material.

Four locations did see the body of the stream become narrower, DM-X11, DM-X15, DM-X16, DM-

X19. Three of these sites were located on the east coast while DM-X19 was found on the west side of Dominica. These streams were all narrower due to an increased presence or new occurrence of cobble banks and bars. The widespread integration of highly coarsegrained material supports the previously mentioned finding suggesting that the East coast of the island experienced similarly strengthened forces. 


\section{CONCLUSION}

Despite having a high average slope across the island, the highly vegetated nature of Dominica allows for a large amount of stability under normal conditions. The presence of large magnitude mass-wasting events is rare, even in the wake of the two most recent largescale weather events. The stability of river channels varies across the island, with GIS analysis indicating that the western coast was more dramatically affected. Though hard to confirm with obscured satellite imagery, the use of ground-truthing and repeat photography appear to be verify these findings. More than half the sites experienced obvious and profound disturbance to vegetation near and along the stream channel due to Hurricane Maria. At most sites there was an increased presence in coarse, rocky material, often replacing previously vegetated banks for cobble bars and banks instead. There were five locations along the west coast which also had newly introduced boulders into the stream profile compared to only two on the east coast. The data and image sets used within this study lead us to believe not all the rivers were affected equally and that there was a westerly bias with the storms.

\section{ACKNOWLEDGEMENTS}

This material is based upon work supported by the Keck Geology Consortium and the National Science Foundation under Grant No. 1659322, in collaboration with the Government of Dominica and Union College. Many thanks to Holli Frey, Laura Waters, Pat Joseph, and the rest of the KECK 2017 students who also participated on this project. I'd like to specifically thank Amanda Schmidt, Kira Tomenchok, Haley Talbot-Wendlandt, and Cole Jimerson for their assistance and support throughout this project. Three other students have also been very influential in keeping this project going: Nathan Daniel, Ely Bordt, and Melinda Quock have all been great partners and co-investigators to work on this data with.

\section{REFERENCES}

Bucknam, R.,C., J. Coe, M. Mota ChavarrÃa, J. Godt, A. Tarr C., L. Bradley, S. Rafferty, D. Hancock, R. Dart L., and M. Johnson L. (2001), Landslides Triggered by Hurricane Mitch in Guatemalaâ€" Inventory and Discussion.

Dominica Meteorological Service (2018), Climate Data, Weather.gov.dm. Available from: http:// www.weather.gov.dm/climate-data (Accessed 15 March 2018)

Frankl, A., J. Nyssen, M. De Dapper, and M. Haile (2011), Linking long-term gully and river channel dynamics to environmental change using repeat photography (Northern Ethiopia), Geomorphology (Amsterdam, Netherlands), 129(3), 238-251.

Hoffman, M. T. and R. F. Rohde (2011), Rivers Through Time: Historical Changes in the Riparian Vegetation of the Semi-Arid, Winter Rainfall Region of South Africa in Response to Climate and Land Use, Journal of the History of Biology, 44(1), 59-80, doi:10.1007/s10739-0109246-4.

Jugaru Tiron, L., J. Le Coz, M. Provansal, and N. Panin (2009), Flow and sediment processes in a cutoff meander of the Danube Delta during episodic flooding, Geomorphology (Amsterdam, Netherlands), 106(3), 186-197.

Khan, S. F., S. F. Khan, U. Kamp, and L. A. Owen (2013), Documenting five years of landsliding after the 2005 Kashmir earthquake, using repeat photography, Geomorphology (Amsterdam, Netherlands), 197, 45-55.

National Oceanic and Atmospheric Administration (2017), Hurricanes, Coast.noaa.gov. Available from: https:/coast.noaa.gov/hurricanes/

(Accessed 15 March 2018)

Long, D. (2017), Geology | | a virtual Dominica, Avirtualdominica.com. Available from: http:// www.avirtualdominica.com/project/geology/

R. Grove, J., J. R. Grove, J. Croke, and C. Thompson (2013), Quantifying different riverbank erosion processes during an extreme flood event, Earth Surf. Process. Landforms, 38(12), 1393-1406. 
Rad, S., P. Louvat, C. Gorge, J. Gaillardet, and C. Allègre (2006), River dissolved and solid loads in the Lesser Antilles: New insight into basalt weathering processes, Journal of Geochemical Exploration, 88(1-3), 308-312, doi:10.1016/j. gexplo.2005.08.063.

Webb, R. H., D. E. Boyer, and R. M. Turner (2010), Repeat photography: methods and applications in the natural sciences, Island Press, Washington. 